\title{
PROTEIN-LOSING ENTEROPATHY AFTER THE FONTAN OPERATION: AN INTERNATIONAL MULTICENTER STUDY
}

Luc Mertens, MD, $\mathrm{PhD}^{\mathrm{a}}$

Donald J. Hagler, $\mathrm{MD}^{\mathrm{b}}$

Ursula Sauer, $\mathrm{MD}^{\mathrm{c}}$

Jane Somerville, $\mathrm{MD}^{\mathrm{d}}$

Marc Gewillig, MD, $\mathrm{PhD}^{\mathrm{a}}$

On behalf of the PLE study group
Objective: This multicenter study retrospectively analyzes the data on 114 patients with protein-losing enteropathy after Fontan-type surgery. Special attention was given to the different treatment strategies used and their effect on outcome. Methods and results: In 35 participating centers 3029 Fontan operations were performed. The incidence of protein-losing enteropathy in the survivors was $3.7 \%$. The median age at Fontan-type surgery was 8.2 years (range: 0.6 to 32.9 years). Median age at diagnosis of protein-losing enteropathy was 11.7 years with a median time interval between surgery and diagnosis of 2.7 years (range: 0.1 to 16.4 years). Most patients had edema (79\%) and effusions (75\%). Hemodynamic data revealed a mean right atrial pressure of $17 \pm$ SD $5.3 \mathrm{~mm} \mathrm{Hg}$ with a cardiac index of $2.4 \pm 0.8 \mathrm{~L} / \mathrm{min} / \mathrm{m}^{2}$. Medical treatment only $(n=52)$ resulted in a complete resolution of symptoms in $25 \%$, no improvement in $29 \%$, and death in $46 \%$. Surgical treatment $(n=52)$ was associated with relief of protein-losing enteropathy in $19 \%$, no improvement in $19 \%$, and death in 62\%. In 13 patients 16 percutaneous interventions were performed. This resulted in symptomatic improvement after 12 interventions and no improvement after 4 interventions. Conclusions: We conclude that the current treatment of protein-losing enteropathy after Fontan operation is associated with a very high mortality and morbidity rate. Preventive strategies and new therapeutic approaches are necessary. ( $J$ Thorac Cardiovasc Surg 1998;115:1063-73)
P rotein-losing enteropathy (PLE) is a rare but life-threatening complication after the Fontan operation. It is speculated that the elevated systemic venous pressures associated with the Fontan circulation cause the intestinal protein loss by increased pressures in the enteric lymphatic system.

Only limited information is presently available on

From the Department of Pediatric Cardiology, UZ Leuven, Leuven, Belgiuma ; the Department of Pediatric Cardiology, Mayo Clinic, Rochester, Minn.'; Deutsches Herzzentrum, München, Germany ${ }^{c}$; and Grown Up Congenital Heart Unit, Royal Brompton and National Heart Hospital, London, United Kingdom. ${ }^{\mathrm{d}}$

Sponsored in part by The Belgian Foundation for Research in Pediatric Cardiology.

Received for publication July 16, 1997; revisions requested August 25, 1997; revisions received Nov. 17, 1997; accepted for publication Nov. 20, 1997.

Address for reprints: Marc Gewillig, MD, Pediatric Cardiology, University Hospitals Leuven, Herestraat 49, B-3000 Leuven, Belgium.

Copyright (C) 1998 by Mosby, Inc.

$0022-5223 / 98 \$ 5.00+0 \quad \mathbf{1 2} / \mathbf{1} / \mathbf{8 7 8 0 1}$ the incidence, the predisposing factors and the hemodynamic profile of patients who have had the Fontan operation and in whom PLE develops. ${ }^{1,2}$ Different treatment strategies have been proposed for PLE after the Fontan operation, but their effect on the outcome remains largely unknown. Reports on successful management are limited. For the management of these difficult conditions it is, however, crucial to know which approach is doomed to fail so that alternative treatment options can be explored. The present study is a retrospective multicenter study reviewing the incidence, hemodynamics, treatment strategies, and outcome of patients with PLE after Fontan-type surgery.

\section{Materials and methods}

Center recruitment. This study is a retrospective multicenter study. The centers were recruited either by e-mail through Pediheart (a server to which professionals involved in the health care of patients with congenital heart disease can subscribe [pediheart@medisun.ucsfresno. edu]) or by regular mail. At the time the study was announced, 588 persons received the e-mail message. Regular mailing was sent to all 470 members of the 
Table I. Pre-Fontan surgery

\begin{tabular}{lcccc}
\hline & \multicolumn{4}{c}{ Palliation } \\
& 1 & 2 & 3 & 4 \\
\hline Age (yr \pm SD) & $2.5 \pm 4.5$ & $4.7 \pm 4.8$ & $7.3 \pm 6.1$ & $3.7 \pm 1.6$ \\
Type of surgery & & & & \\
$\quad$ Blalock-Taussig & 33 & 25 & 0 & 1 \\
Banding PA & 24 & 5 & 0 & 0 \\
Central shunt & 10 & 6 & 4 & 2 \\
Glenn & 7 & 1 & 2 & 0 \\
Bidirectional Glenn & 1 & 6 & 0 & 0 \\
Atrial septostomy & 4 & 0 & 1 & 0 \\
Norwood I & 3 & 0 & 0 & 0 \\
Commisurotomy PV & 4 & 0 & 1 & 0 \\
VSD closure & 1 & 0 & 0 & 0 \\
VSD enlargement & 1 & 0 & 1 & 0 \\
Mitral valve surgery & 1 & 1 & 0 & 0 \\
Other & 7 & 3 & 5 & 1 \\
Total & 96 & 47 & 14 & 4 \\
\hline
\end{tabular}

$S D$, Standard deviation; $P A$, pulmonary artery; $P V$, pulmonary valve; $V S D$, ventricular septal defect.

European Association of Pediatric Cardiologists. Thirtyfive centers (listed at the end of the paper) finally submitted data. Collection of data was started in August 1995 and stopped in December 1996.

Patient selection. A study questionnaire was filled out for each patient who had had Fontan-type surgery and in whom clinical symptoms of documented hypoproteinemia (edema, effusions) due to PLE developed. Other causes of hypoproteinemia such as liver failure and renal protein loss needed to be excluded.

In addition, the centers were asked to submit data as to the number of Fontan operations that had been performed, perioperative mortality rates, and follow-up procedures. This allowed an assessment of the incidence of PLE after Fontan-type surgery. Because of incomplete data sets, detailed information could not be gathered on the other patients without PLE who have had Fontan operations.

Fontan surgery. Descriptive statistics were performed on the data. The primary outcome variable was the effect of treatment on the PLE (death, no change, improved, cured). In every patient with PLE, all the requested information was obtained. Student's $t$ test, $\chi^{2}$ test, correlation analysis with Fisher's $r$ to $\mathrm{z}$ transformation were applied where appropriate. Survival analysis was performed by the Kaplan-Meier estimation. For the comparison of subgroup survival Mantel-Cox log rank analysis was performed. Statistical analysis was performed with the software programs Statview 4.5 (Abacus Concepts, Berkeley, Calif.) and GB-stat 6.0 (Dynamic Microsystems, Silver Spring, Md.).

\section{Results}

General patient data. In total, 3029 Fontan-type operations were performed in 35 participating centers. The operations were performed between 1975 and 1995. The number of Fontan operations performed in each center ranged between 4 and 839
Table II. Pre-Fontan hemodynamic data

\begin{tabular}{lcrrrc}
\hline & Number & Mean & SD & Minimum & Maximum \\
\hline Sat Ao & 99 & 81.5 & 6.7 & 51.0 & 96.0 \\
PAP (mean) & 83 & 16.4 & 7.2 & 6.0 & 41.0 \\
PVR & 62 & 1.9 & 1.2 & 0.2 & 5.6 \\
Nakata & 42 & 291.0 & 95.4 & 100.0 & 508.0 \\
McGoon & 28 & 2.1 & 0.8 & 1.0 & 3.9 \\
Cardiac index & 47 & 4.1 & 1.4 & 1.2 & 7.4 \\
Mean LAP & 86 & 9.0 & 5.2 & 2.0 & 28.0
\end{tabular}

$S D$, Standard deviation; Sat $A o$, saturation aorta; $P A P$, pulmonary artery pressure; $P V R$, pulmonary vascular resistance; $L A P$, left atrial pressure.

(median: 54). The early mortality rate ( $<30$ days after surgery) ranged between $0 \%$ and $41.7 \%$, with a mean of $13.3 \pm$ standard deviation $9.5 \%$. The total number of patients in follow up who have undergone Fontan operations was 2584 (median for each center: 40; range: 3 to 764 patients). PLE was diagnosed in 114 patients. The 3.8\% incidence of PLE is relative to the total number of Fontan-type operations and $4.2 \%$ relative to the number of early survivors. The incidence of PLE relative to the total number of Fontan operations in each center varied between $0 \%$ and $25 \%$. Neither the number of Fontan operations performed in each center nor the early mortality rates correlated significantly with the incidence of PLE.

Data on all 114 patients with PLE were obtained (72 male and 42 female). The cardiac diagnosis was tricuspid atresia in 36 patients $(31.6 \%)$, double-inlet left ventricle in 33 patients (29\%), and other forms of "complex univentricular heart" in 45 patients $(39.4 \%)$. The last group contained diverse complex congenital heart defects such as atrioventricular canal-type of malformation (8), double-outlet right ventricle (8), mitral atresia (4), single-inlet ventricle (4), L-transposition of the great arteries plus severe pulmonary stenosis (4), double-inlet right ventricle (2), hypoplastic left heart syndrome (2), pulmonary atresia with intact ventricular septum (2), and other forms of "functional univentricular heart" (10).

Heterotaxy syndrome was present in three patients: two patients with asplenia and one patient with polysplenia. Four patients had situs inversus, and one patient had situs ambiguus.

In 97 of 114 patients (85\%) palliative surgery was performed before the Fontan operation. The different types of pre-Fontan palliation and the age at which pre-Fontan surgery was performed are summarized in Table I. In total, 62 of $114(53 \%)$ patients, when initially seen, had low pulmonary blood flow that caused cyanosis; 33 of 114 (28\%) 
patients had high pulmonary blood flow that required a banding type of operation to protect the pulmonary circulation. In this series, initial banding was performed at a median age of 0.6 years (range: 3 days to 3.4 years); five patients were banded twice. In 19 of $114(19 \%)$ patients, the initial lung flow was "balanced" and surgical palliation before the Fontan operation was not performed.

Pre-Fontan hemodynamic data. A preoperative cardiac catheterization was performed in 106 of 114 patients $(93 \%)$. Table II summarizes the hemodynamic measurements obtained before the Fontan operation. Data on preoperative atrioventricular valve regurgitation were available on 92 patients. Of 92 patients, atrioventricular valve regurgitation was described as absent in 64 $(69.5 \%)$ patients, mild in $18(19.5 \%)$ patients, moderate in $5(5.5 \%)$ patients, and severe in 5 $(5.5 \%)$ patients.

Fontan-type surgery. Fontan-type surgery was performed at a median age of 8.2 years (range: 0.6 to 32.9 years). The operation was performed in 70 of 114 patients $(61.4 \%)$ before 1987 and in 44 of 114 patients $(38.6 \%)$ after 1987.

The time distribution of the series reflects changes in surgical techniques. In 114 patients, an atrioventricular connection was performed in 22 $(19.3 \%)$; an atriopulmonary connection was performed in $75(65.8 \%)$; and a total cavopulmonary connection (with total or subtotal exclusion of the right atrium) was performed in 17 (14.9\%). Thus no type of connection is free of PLE after Fontan surgery.

The early postoperative course was characterized by a median intensive care unit stay of 8 days (range: 2 to 50 days), a median postoperative hospitalization duration of 26 days (range: 8 to 150 days), and a requirement for chest tube drainage during 12 days (median range: 0 to 135 days). Postoperative complications were ascites $(n=17)$, renal failure $(n=$ $13)$, arrhythmia $(n=26)$, respiratory problems $(n=$ $8)$, wound infection $(n=5)$, unilateral diaphragmatic paralysis $(n=3)$, and neurologic complications $(n=2)$.

In 12 patients additional surgery was performed between the initial Fontan operation and the time PLE was diagnosed. This included closure of a leak in the atrioventricular-valve patch (4), atrioventricular-valve replacement (3), pacemaker implantation (3), plication of the diaphragm (1), and aortic valve replacement (1). In one patient angioplasty of the pulmonary artery was performed.
Table III. Other complications in patients with PLE

\begin{tabular}{lc}
\hline \multicolumn{1}{c}{ Complication } & $\begin{array}{c}\text { No. of } \\
\text { patients }(\%)\end{array}$ \\
\hline Hypocalcemia & $38(33)$ \\
Infections & $19(16)$ \\
Sepsis & 9 \\
Respiratory infections & 8 \\
Cholecystitis & 2 \\
Recurrent cellulitis & 3 \\
Herpes simplex infection & 1 \\
Pneumococcal peritonitis & 1 \\
Thromboembolic complications & $21(18)$ \\
Right atrial thrombus & 12 \\
Pulmonary artery thrombus & 4 \\
Ventricular thrombus & 2 \\
Cerebrovascular accident & 5 \\
Pulmonary embolism & 5 \\
Arrhythmia & $32(28)$ \\
Atrial flutter & 9 \\
Atrial fibrillation & 6 \\
Supraventricular tachycardia & 8 \\
Junctional rhythm & 4 \\
Supraventricular ectopy & 1 \\
Atrioventricular block & 4 \\
\hline
\end{tabular}

Clinical diagnosis of PLE and hemodynamic evaluation. As mentioned in the Materials and methods section, PLE was defined in this study as the occurrence of clinical symptoms related to documented hypoproteinemia caused by intestinal loss. Other causes of hypoproteinemia had to be excluded. Moreover, subclinical gastrointestinal protein loss was not considered an inclusion criterion for the present study.

At the time of diagnosis of PLE, the patients had edema $(79 \%)$, ascites $(53 \%)$, pleural effusion(s) $(22 \%)$, and/or chronic diarrhea $(11 \%)$. Other symptoms or clinical findings present at the time of diagnosis were dyspnea (5\%), fatigue $(3.5 \%)$, abdominal fullness $(5 \%)$, carpopedal spasms $(1.7 \%)$, and a pericardial effusion $(1.7 \%)$. The other complications are summarized in Table III.

The median time interval between Fontan-type surgery and the occurrence of PLE was 2.7 year (range: 1 month to 16.4 years).

In all patients either total protein and/or serum albumin measurements were obtained. In 89 of 114 patients the serum albumin level at the time of diagnosis was $2.4 \pm 0.6 \mathrm{gm} / \mathrm{dl}$ (normal value: 3.5 to $5.5 \mathrm{gm} / \mathrm{dl}$ ). In 55 of 114 patients the total protein level was $4.3 \pm 0.8 \mathrm{gm} / \mathrm{dl}$ (normal value: 5.5 to 8.0 $\mathrm{gm} / \mathrm{dl}$ ). The gastrointestinal protein loss was quantified by calculating the $\alpha_{1}$-antitrypsin clearance in 
Table IV. PLE hemodynamic data

\begin{tabular}{lcrrcc}
\hline & Number & Mean & SD & Minimum & Maximum \\
\hline Sat Ao & 60 & 90.1 & 6.7 & 63.0 & 99.0 \\
Sat MV & 56 & 64.0 & 8.8 & 41.0 & 71.0 \\
RAP & 79 & 17.0 & 5.3 & 8.0 & 38.0 \\
PAP & 77 & 16.3 & 6.1 & 6.0 & 40.0 \\
VEDP & 59 & 9.5 & 5.6 & 0.0 & 37.0 \\
PVR & 30 & 2.9 & 1.6 & 0.3 & 7.7 \\
CI & 53 & 2.4 & 0.8 & 0.6 & 5.9
\end{tabular}

$S D$, Standard deviation; Sat Ao, saturation aorta; Sat $M V$, mixed venous saturation; $R A P$, mean right atrial pressure; $P A P$, mean pulmonary artery pressure; $V E D P$, ventricular end-diastolic pressure; $P V R$, pulmonary vascular resistance; $C I$, cardiac index.

27 patients. The mean value was $432 \pm 370 \mathrm{ml} / 24 \mathrm{hr}$ (normal value $<27 \mathrm{ml} / 24 \mathrm{hr}$ ). In seven patients gastrointestinal protein loss was quantified by intravenously administered ${ }^{51}$ chromium-labeled albumin. An increased enteric protein loss was demonstrated by an increased excretion of the labeled albumin in the stools: $22.7 \% \pm 7.2 \%$ of the injected radioactive label (normal: $<2.0 \%$ ).

In $83(73 \%)$ of 114 patients hemodynamic evaluation by cardiac catheterization was performed after PLE was diagnosed. Table IV summarizes the basic hemodynamic measurements obtained during catheterization. These data are, however, difficult to interpret because nearly all of the patients were receiving significant doses of diuretics at the time of catheterization. Of special note are the mean cardiac index of $2.4 \pm 0.8 \mathrm{~L} / \mathrm{kg} / \mathrm{min}$ and the mean right atrial pressure of $17.0 \pm 5.3 \mathrm{~mm} \mathrm{Hg}$. In 29 patients a gradient was reported to be present in some part of the Fontan connection. In 22 patients numeric data for gradients were available (mean: $4.3 \pm 3.0$ $\mathrm{mm} \mathrm{Hg}$; range: 2 to $15 \mathrm{~mm} \mathrm{Hg}$ ). Other findings of relevance included intrapulmonary shunting (5), residual connection single ventricle-pulmonary artery (3), atrioventricular valve patch leak (1), obstruction of pulmonary venous return (2), obstruction of the atrial baffle from the hepatic veins to the pulmonary artery (1), venovenous collaterals (3), residual Blalock-Taussig shunt (1), diaphragmatic paralysis (3), and coronary artery ligation (1). Atrioventricular valve regurgitation was present in 29 patients (severe [5], moderate [12], and mild [12]). Ventricular dysfunction was present in 24 patients (severe [9], moderate [9]). In two patients a marked bradycardia associated with sinus node dysfunction and nodal rhythm was present.

Treatment and outcome of PLE. Patients in whom PLE develops after the Fontan operation have a poor prognosis with a 5 -year survival of 59\% and a total mortality rate of $50 \%$ in the present study. The Kaplan-Meier survival analysis is shown in Fig. 1.

In the treatment of PLE, a wide variety of different approaches have been tried. Three main treatment options can be identified. First, a purely noninvasive treatment consisting of drug treatment (diuretics, afterload reduction, inotropic agents, and steroids) and diet (low fat and high protein) and/or protein infusions can be used. Second, surgery can be performed to improve the Fontan hemodynamics. Third, a nonsurgical interventional approach can be used, including fenestration of the atrial septum and balloon dilation of a pathway obstruction.

In our patient population, $52(45.6 \%)$ patients were treated noninvasively, $52(45.6 \%)$ patients received a surgical intervention, and 10 (8.8\%) patients received a percutaneous intervention.

Medical treatment only was given to 52 patients. An overview of treatments used in this group is shown in Table V. Most patients were treated with a combination of diuretics, digoxin, afterload reduction, and diet. Albumin infusions were given intermittently in 28 of 52 patients. Additional medication was given to 32 of 52 patients. This medical approach resulted in a subjective improvement with resolution of the PLE symptoms in 13 of $52(25 \%)$ patients. In 15 of $52(28.8 \%)$ patients some improvement was observed, but the patients remained symptomatic (alive with PLE). Twenty-four (46.2\%) patients from this treatment group died.

Surgery was performed in 52 of 114 patients. The median interval between the diagnosis of PLE and surgery was 1.0 year (range: 0.01 to 8.0 years). The median age at operation was 14.6 years (range: 2.5 to 45.3 years). The interval between the Fontan operation and the redo operation for PLE was 4.5 years (range: 0.6 to 16.5 years). A wide variety of surgical approaches were tried (Table VI). The first type of operation was surgery aimed at optimizing the Fontan circuit either by conduit surgery, valve surgery, or ventricular septal defect surgery. A second type of operation involved the conversion of a type of Fontan circuit (for example, atrioventricular connection converted into atriopulmonary connection). This operation was performed either because of a mechanical problem with the existing Fontan circuit or because the new type of circuit was thought to be hemodynamically more favorable. A third type of operation is defined as a Fontan takedown. In a fourth subgroup of patients, heart transplantation was performed. 


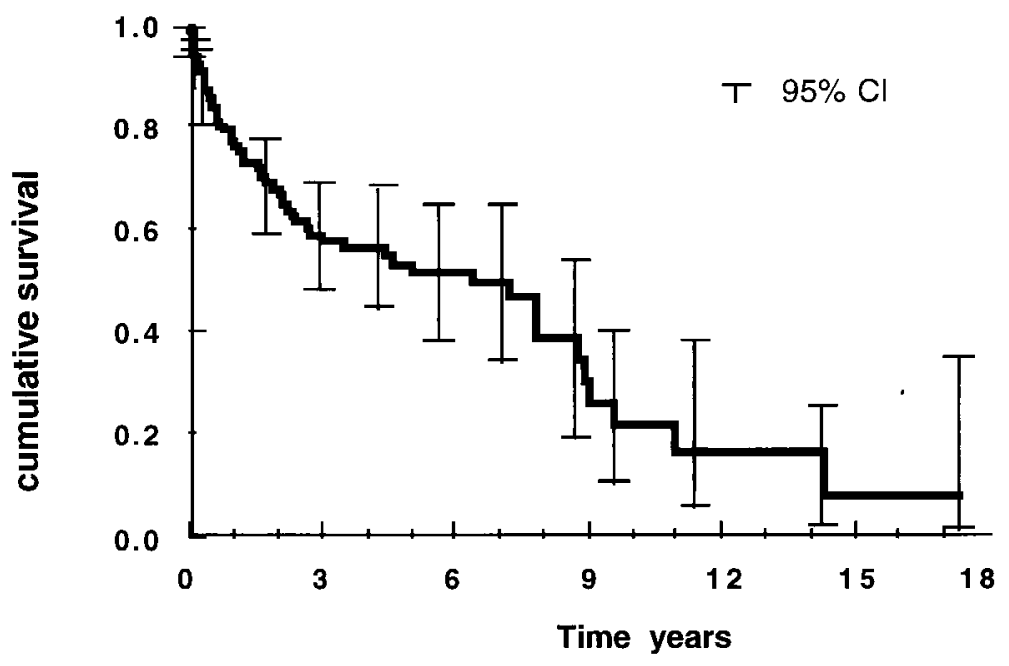

Fig. 1. Survival analysis (Kaplan-Meier) of patients with PLE. The graph represents a Kaplan-Meier survival analysis. Time zero represents the date of diagnosis of PLE. The vertical bars represent the $95 \%$ confidence interval.

The outcome of surgery is presented in Table VII. A very high overall mortality rate $(61.5 \%)$ is associated with PLE surgery. Most of the deaths occur in the early postoperative period $(81 \%$ within 3 months after the operation). Although the groups are relatively small, all different surgical approaches seem to result in a poor outcome. Even heart transplantation appeared to have a high mortality rate, with two deaths in five patients. There is also one patient in whom the PLE symptoms did not resolve after transplantation.

In 13 patients interventional catheterization were performed. In three patients the interventional approach was combined with a surgical approach. Three types of interventional procedures were performed in the patients with PLE. The first type involved a balloon dilation with or without stenting of a stenosis on the Fontan-type connection or of a stenosis on the pulmonary artery (nine interventions). The second type of intervention involved percutaneously creating a fenestration in the intraatrial septum (five interventions). In one patient, systemic-pulmonary artery collaterals were occluded with coils.

Nine balloon dilations with four stent placements were performed, three because of a stenosis in the Fontan circuit and six for a stenosis in a pulmonary artery. The mean gradient before balloon dilation was $4.8 \pm 4.4 \mathrm{~mm} \mathrm{Hg}$ that was reduced to $2.0 \pm 1.9$ $\mathrm{mm} \mathrm{Hg}$ after the procedures. In eight cases the procedure was considered successful with a signifi- cant decrease in gradient or in increase in blood flow. In one patient a balloon dilation of the inferior cavopulmonary anastomosis was unsuccessful with no reduction in gradient. Of the eight successful procedures, three had no effect on PLE and three resulted in a long-lasting symptomatic improvement (in one patient this occurred after further surgery); in two patients only a temporary improvement was obtained with a recurrence of PLE symptoms within a few months after the procedure.

Five fenestrations in the intraatrial septum were created percutaneously with different techniques. In three patients the fenestration was created by blade septectomy combined with progressive balloon dilation of the fenestration. In one patient the intraatrial septum was punctured, and progressive balloon dilations of the puncture hole were performed. In one patient a stent was placed in the fenestration. The time interval between the diagnosis of PLE and the fenestration was 1.6 years (median range: 0.2 to 5.1 years). The median age at fenestration was 17.9 years (range: 2.8 to 41.7 years). The median time interval between the creation of the fenestration and the time of Fontan surgery was 8.5 years (range: 1.6 to 10.7 years). In three of the five patients a marked effect was observed on the PLE symptoms with nearly complete resolution of all symptoms. In the remaining two patients only a mild improvement was observed. In two patients a stroke occurred after the fenestration was created. One of these patients was not given anticoagulants after the fenestration. 
Table V. Overview of medical treatment

\begin{tabular}{|c|c|c|}
\hline Treatment & $\begin{array}{l}\text { No. of patients } \\
\text { receiving } \\
\text { medical } \\
\text { treatment only* } \\
(\%)\end{array}$ & $\begin{array}{l}\text { Total no. } \\
\text { of patients in } \\
\text { PLE group } \dagger\end{array}$ \\
\hline Diuretics & $51(98)$ & $109(96)$ \\
\hline Furosemide only & 19 & 41 \\
\hline Spironolactone only & 1 & 4 \\
\hline $\begin{array}{l}\text { Furosemide }+ \\
\quad \text { Spironolactone }\end{array}$ & 30 & 62 \\
\hline Other & 1 & 2 \\
\hline Positive inotropic agents & $42(81)$ & $91(80)$ \\
\hline Digoxin/digitoxin & 42 & 87 \\
\hline Dopamine & 0 & 3 \\
\hline Afterload reduction & $37(71)$ & $67(59)$ \\
\hline ACE-I & 32 & 61 \\
\hline Hydralazine & 2 & 2 \\
\hline Other & 3 & 4 \\
\hline Steroids & $3(5.7)$ & $16(14)$ \\
\hline Hydrocortisone & 0 & 1 \\
\hline Prednisone & 0 & 7 \\
\hline Prednisolone & 0 & 4 \\
\hline Methylprednisolone & 3 & 4 \\
\hline Protein infusions & $28(54)$ & $67(59)$ \\
\hline Albumin $20 \%$ & 24 & 61 \\
\hline Gamma globulins & 5 & 8 \\
\hline Plasma & 1 & 2 \\
\hline Diet & $42(81)$ & $79(69)$ \\
\hline High protein & 29 & 61 \\
\hline Low fat & 21 & 43 \\
\hline High protein-low fat & 18 & 32 \\
\hline MCT & 6 & 15 \\
\hline Other medication & $32(61)$ & $60(53)$ \\
\hline Anticoagulants & 7 & 19 \\
\hline Aspirin & 7 & 17 \\
\hline Antiarrhythmics & 14 & 33 \\
\hline Other & 3 & 5 \\
\hline
\end{tabular}

$A C E-I$, Angiontensin-converting enzyme inhibitors; $M C T$, medium-chain triglycerides.

${ }^{*} N=52$.

$\dagger N=114$.

In one patient systemic-pulmonary artery collaterals were closed by coil placement, but this did not improve intestinal protein loss.

Fig. 2 represents the Kaplan-Meier survival analysis for the three different treatment groups. Log rank analysis could not demonstrate a significant effect of treatment option on PLE survival (Table VIII).

The effect of steroid treatment on PLE. Because steroids have been added to the treatment in the different treatment groups, their effect on PLE is discussed separately. Steroids have been added to the treatment in 16 patients. Seven patients in the surgical treatment group received steroids: five pa- tients before the intervention and two patients after the operation. It is evident that in those patients in whom surgery was performed after steroid treatment, steroid treatment was not sufficiently effective. Six patients of the interventional catheterization group were also treated with steroids. Four patients received steroids after the intervention and two patients before it. In three patients of the medication-only group, steroids were added to the treatment. All patients were treated with reducing dosing schemes. Steroid treatment resulted in a marked symptomatic improvement in 5 of 16 patients, with nearly complete disappearance of all PLE symptoms. Four of these patients, however, required prolonged administration of a low maintenance dose. In 7 of 16 patients some subjective symptomatic improvement was obtained without complete disappearance of all PLE symptoms. In four patients no effect could be noted.

\section{Discussion}

This multicenter study summarizes the clinical characteristics and treatment outcomes of patients with PLE after Fontan-type surgery. It confirms that PLE is a rare complication after Fontan-type surgery that is associated with a poor prognosis. Whatever treatment strategy is used, the prognosis of patients with PLE after Fontan-type surgery is poor.

Clinical characteristics of patients in whom PLE develops after Fontan surgery. In a recent study Feldt and associates ${ }^{1}$ overviewed the clinical characteristics of the Mayo Clinic patients in whom PLE developed after a Fontan operation. They studied a total of 427 patients who survived for 30 days after a Fontan operation performed between July 1973 and January 1987. In 47 of $427(11 \%)$ patients PLE developed during follow up. Univariate and multivariate analysis indicated that the factors associated with the development of PLE were ventricular anatomy (other anatomy than dominant left ventricle), increased preoperative ventricular end-diastolic pressure, longer operative bypass time, increased length of hospital stay, and postoperative renal failure. In the present study a multivariate analysis could not be performed because the data on the patients in whom PLE did not develop after Fontan surgery could not be obtained. However, in the patients described in the present study (which also includes the Mayo Clinic data), several of these risk factors seem to be present.

The preoperative hemodynamic evaluation shows that some of the patients in whom PLE develops 
after Fontan surgery would nowadays no longer be scheduled for Fontan surgery (for instance, a patient with a pulmonary vascular resistance of 5.6 units $/ \mathrm{m}^{2}$ or a patient with a mean pulmonary artery pressure of $41 \mathrm{~mm} \mathrm{Hg}$ ). Because some of these patients had been initially treated in the pre-Fontan era, the pre-Fontan palliations used reflect a historical evolution in the treatment of univentricular hearts. This is demonstrated by the wide variation of different initial palliative techniques, with some patients having had suboptimal pre-Fontan procedures with poor timing (banding at $0.9 \pm 0.9$ year). This resulted in prolonged and excessive volume loading of the ventricle and elevated pulmonary vascular resistance in some of the later patients with PLE. This certainly contributed to a difficult early postoperative course in some of these patients (such as, with pleural effusions, renal failure). Although we have no reference values, a mean hospitalization stay of 26 days seems long after a Fontan operation.

Remarkable in the present study is the predominance of patients with a left ventricular morphologic condition $(68 \%)$, with only $18 \%$ of all patients with PLE having a right ventricular morphologic condition. In $14 \%$ of all patients ventricular morphologic condition could not be determined. This distribution is to be compared to the whole Fontan population, but it shows that further study is required to better identify the risk factors associated with PLE.

PLE hemodynamics and pathophysiology. PLE in cardiac disease is mostly associated with disorders in which chronically elevated systemic venous pressures and especially elevated superior caval venous pressures are present (constrictive pericarditis, ${ }^{4}$ long-standing congestive heart failure, ${ }^{5}$ baffle obstruction after the Mustard operation for transposition of the great arteries ${ }^{6}$; after the Glenn operation $^{7}$ and Fontan operation ${ }^{1,2,8-11}$ ). The exact pathophysiology of PLE is unknown. It is hypothesized that chronic venous congestion with elevated superior vena caval pressures leads to disturbed lymph drainage through the thoracic duct. ${ }^{10}$ Moreover, the increased inferior vena caval and portal vein pressures lead to increased intestinal congestion and lymph production. Proteins and lymphocytes leak from the dilated lymphatics. This functional disorder may progress to intestinal lymphangiectasia. Maybe an inflammatory response caused by chronic congestion or leakage of proteins from the enteric lymphatic system is also involved in the pathogenetic process. The beneficial therapeutic
Table VI. Different types of operations

\begin{tabular}{lc}
\multicolumn{1}{c}{ Type of operation } & $\begin{array}{c}\text { No. of } \\
\text { patients }\end{array}$ \\
\hline Optimizing Fontan circuit & 26 \\
Conduit surgery & 12 \\
Conduit surgery + atrioventricular valve replace- & 1 \\
ment & \\
Plasty tricuspid valve & 1 \\
Plasty mitral valve + ASD closure & 1 \\
Plasty mitral valve + VSD closure & 1 \\
Atrioventricular valve replacement + subaortic & 2 \\
$\quad$ stenosis resection & \\
Closure ventricle-pulmonary artery connection & 3 \\
Patch enlargement pulmonary artery & 2 \\
Surgical closure atrioventricular valve & 1 \\
VSD enlargement & 1 \\
Excision intraatrial patch hepatic veins-pulmo- & 1 \\
nary artery & \\
Conversion-type Fontan circuit & 13 \\
RAPA > TCPC & 5 \\
RAPA > fenestrated RAPA & 1 \\
RAPA > CPAP & 1 \\
RARV > RARV + BDG & 1 \\
RARV > RAPA & 3 \\
CPAP > fenestrated TCPC & 1 \\
TCPC $>$ fenestrated TCPC & 1 \\
Fontan takedown & 4 \\
Heart transplantation & 5 \\
Other interventions & 4 \\
\hline A D & \\
\hline
\end{tabular}

$A S D$, Atrial septal defect; $V S D$, ventricular septal defect; $R A P A$, right atrial to pulmonary connection; TCPC, total cavopulmonary connection; $C P A P$, cavopulmonary atriopulmonary connection; $R A R V$, right atrial to right ventricle connection; $B D G$, bidirectional Glenn.

effect of steroids observed in some patients could be explained by suppression of this inflammatory reaction. ${ }^{12-14}$ No consistent effect of steroids can, however, be found, which indicates that additional mechanisms are probably involved. The actual molecular basis for PLE remains unknown. It has been shown that sulphated glycosaminoglycans may be important in regulating vascular and renal albumin loss. In a recent paper three children with PLE were shown to have an enteric heparin sulfate deficiency. ${ }^{15}$ In those three infants a complete absence of enterocyte heparin sulphate was found by histochemistry. The recent finding that high molecularweight heparin improves PLE after the Fontan operation $^{19}$ could be consistent with this. Chronic congestion could interfere with the production and distribution of heparin sulfate leading to intestinal albumin loss. Another possibility is a disturbance in endothelial function in the lymphatic system. The exact pathophysiologic mechanism presently remains obscure and requires further study. Especially the impact of chronically elevated systemic venous 
Table VII. Outcome of surgery

\begin{tabular}{lcccc}
\hline \multicolumn{1}{c}{ Type of surgery } & Death & $\begin{array}{c}\text { Alive } \\
\text { with PLE }\end{array}$ & $\begin{array}{c}\text { Alive } \\
\text { no PLE }\end{array}$ & Total \\
\hline Optimizing Fontan & 17 & 5 & 4 & 26 \\
Conversion Fontan & 6 & 4 & 3 & 13 \\
Takedown & 3 & 0 & 1 & 4 \\
Cardiac transplant & 2 & 1 & 2 & 5 \\
Other & 4 & 0 & 0 & 4 \\
Total (\%) & $32(61.5)$ & $10(19.2)$ & $10(19.2)$ & 52 \\
\hline
\end{tabular}

PLE, Protein-losing enteropathy.

pressures on intestinal lymphatic functioning should further be explored in experimental studies.

Because systemic venous pressure is the driving force for the pulmonary circulation in a Fontan circulation, chronic venous congestion is always present. It is not known why intestinal protein loss therefore occurs in a small percentage of patients. Our data suggest that not only hemodynamic factors are involved in the process of PLE but that the complication may result from a combination of unfavorable factors. Increased systemic venous pressures are certainly not the only underlying factor because, in $23 \%$ of the patients with PLE in whom right atrial pressures were obtained, mean right atrial pressure was below $15 \mathrm{~mm} \mathrm{Hg}$ (a "good" value for a patient after a Fontan operation). Even in those patients where an unfavorable hemodynamic factor was detected on hemodynamic evaluation (e.g., stenosis on the conduit), improvement of the hemodynamics (e.g., removal of the stenosis) did not always result in improvement of PLE. These are patients in whom the Fontan circulation is not tolerated without any good explanation. It may be that the intestinal lymphatic system operates at the limit of its capacities in all patients after the Fontan operation but only fails in a small percentage of patients. Structural and physiologic differences in lymphatic function could explain the occurrence of PLE but these are extremely difficult to study. Another possibility is that the standard hemodynamic evaluation methods in these patients fail to uncover hemodynamic disturbances causing PLE. Especially the evaluation of right atrial pressures and pulmonary vascular resistance in patients who have been aggressively treated with diuretics before the cardiac catheterization is questionable. Other factors such as pulmonary vascular reactivity may not be adequately evaluated during catheterization.

PLE treatment and outcome. Different treatment options have been tried in patients in whom PLE
Table VIII. Final outcome of PLE

\begin{tabular}{lcccr}
\hline & \multicolumn{3}{c}{ Alive +} & Alive no \\
& $\begin{array}{c}\text { Death } \\
(\%)\end{array}$ & $\begin{array}{c}\text { PLE } \\
(\%)\end{array}$ & $\begin{array}{c}\text { PLE } \\
(\%)\end{array}$ & Total \\
\hline Medical treatment & $24(46.2)$ & $15(28.8)$ & $13(25)$ & 52 \\
Intervention & $1(10)$ & $5(50)$ & $4(40)$ & 10 \\
Surgery & $32(61.6)$ & $10(19.2)$ & $10(19.2)$ & 52 \\
Total & $57(50)$ & $30(26)$ & $27(24)$ & 114 \\
\hline
\end{tabular}

develops after the Fontan operation, but only a few successful approaches have been published. ${ }^{12-14,16-20}$

Our patients experienced a wide variety of different treatment strategies. To organize the different treatment options, we categorized our patients into three different classes: purely medical treatment, surgical treatment, and treatment by interventional catheterization. This division is somewhat arbitrary, because all patients who underwent surgical treatment were also receiving medication. Moreover the "surgery" group is a very heterogeneous group going from Fontan redo surgery to Fontan takedown and heart transplantation. No relation between strategy and outcome of PLE was observed.

Medical treatment was aimed at some symptomatic relief (diuretics, intermittent infusion of albumin) to improve hemodynamics (digitalis, ventricular afterload reduction), to influence an unknown mechanism (steroids), or to prevent further complications (antiarrhythmics, anticoagulation). Results were disappointing, and this probably reflects, in most cases, the natural history of PLE after the Fontan operation.

Surgery in patients with PLE was associated with a very high mortality rate. Especially in patients with ventricular dysfunction, atrioventricular-valve insufficiency, or increased pulmonary vascular resistance, mortality rate is extremely high. Poor hemodynamics and chronic hypoproteinemia with resulting catabolism probably compromised the outcome of major cardiac surgery. In this context it should be noted that a long time interval between the diagnosis of PLE and the time of surgery was observed in the present study (mean: 1.8 years; range: 0.01 to 8.0 years). Reluctance of the cardiologist or the surgeon to perform major surgery in a "mildly" symptomatic patient probably caused a major delay in many cases. Of those patients with PLE who survived surgery, only $50 \%$ were cured of PLE after surgery. This could be due to insignificant improvement in hemodynamics after surgery. So, for instance, converting one type of Fontan circulation into another 


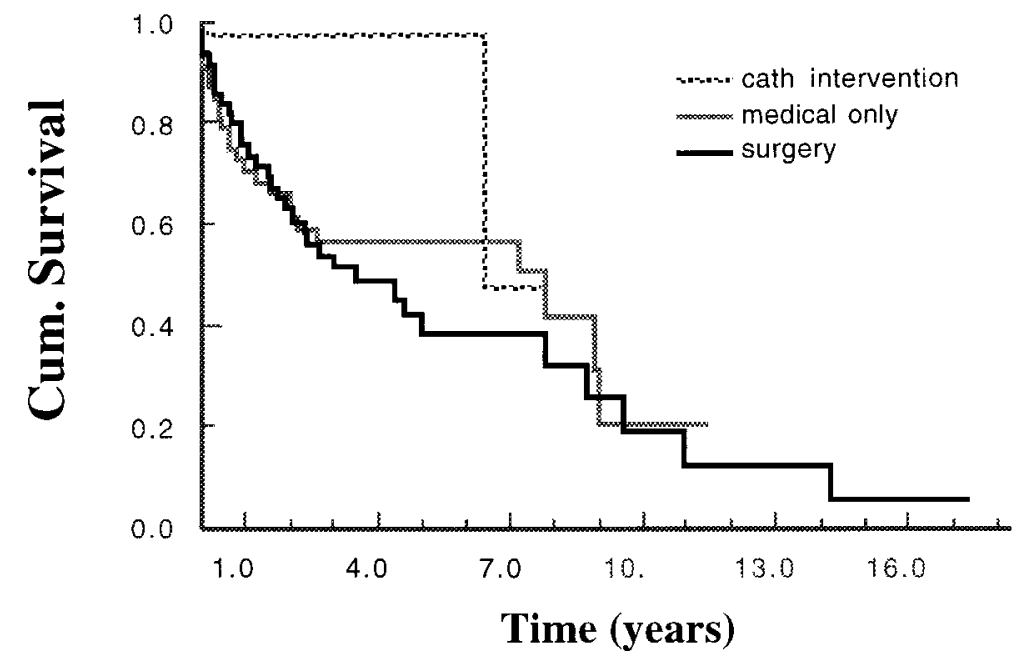

Fig. 2. Survival analysis of different treatment groups. A Kaplan-Meier analysis of the different treatment subgroups is represented. Time zero represents the date of diagnosis of PLE. Log rank analysis did not show a significant effect of treatment on survival.

type of circuit may not result in a hemodynamic amelioration that is sufficient to cure PLE. In vitro hemodynamic studies and computer simulations have shown that some types of Fontan circuits are hemodynamically more favorable than others. ${ }^{20-23} \mathrm{It}$ seems that if a patient is not tolerating one type of circuit, the small differences in energy loss between the different surgical connections may not really be clinically relevant. Also the changes in the enteric system may become irreversible and not responsive even to normalization of the hemodynamics. In one cardiac transplant patient, PLE resolved completely in the immediate postoperative period but recurred a few years after surgery despite good hemodynamics. Thus the effect of transplantation on PLE after Fontan surgery also requires further study.

Because of the high risk associated with surgery, interventional procedures to optimize the Fontan circuit are a potential alternative. Different types of interventions were performed. The balloon dilations and stent placements resulted in symptomatic improvement in most patients. However, only one patient was actually considered as not having symptomatic protein loss after the procedure. Previous reports have already mentioned a beneficial effect of fenestrating the intraatrial septum on PLE. ${ }^{16-18,24}$ This is confirmed in the present study where a fenestration was performed with improved Fontan hemodynamics in five patients and reduced protein loss after the procedure in all patients. It is the only treatment where a consistent positive effect was observed. However, in two patients a thromboembolic event occurred with neurologic complications that indicated the absolute requirement for anticoagulation before and after the fenestration. Moreover, there was a high tendency for the percutaneous fenestrations to close spontaneously with deterioration of PLE symptoms. Newer techniques like stent placement in the intraatrial septum could prevent this, but only limited experience is presently available. $^{25}$

Limitations of the study. It is evident that this study has the limitations of any multicenter clinical study, such as center differences in patient evaluation. Moreover, this study has the limitations of any retrospective study that comprises incompleteness of data, making conclusions very difficult. An additional limitation is the absence of a control group of patients who underwent a Fontan operation and in whom PLE did not develop. Ideally we should have obtained data on all 2854 patients who are still in follow-up in the 35 participating centers, but this was practically unfeasible. Maybe the creation of an international Fontan registry could help for studying more rare complications of this operation.

\section{Conclusion: Therapeutic strategies for PLE after Fontan surgery}

Because enteric lymphatic function is impossible to evaluate, only the Fontan hemodynamics can be directly assessed after the diagnosis of PLE is made. Therefore, the moment the diagnosis is suspected, 
an immediate, careful, complete hemodynamic evaluation with catheterization is required. When a hemodynamic lesion that can be treated by therapeutic intervention (e.g., pulmonary artery stenosis) is detected, this should be immediately managed. Fenestration should be considered if there is no residual lesion to treat. Full anticoagulation is indicated before and after the fenestration. Surgery should be performed before cachexia develops. Significant ventricular dysfunction or atrioventricular valve regurgitation are important contraindications for reoperation. The patient's general condition should be optimized before surgery. A trial with high-dose steroid treatment or subcutaneous high molecular weight heparin may be used. Heart transplantation should be considered before chronic PLE with eventual irreversible changes in the enteric lymphatic system develops.

\section{REFERENCES}

1. Feldt R, Driscoll D, Offord K, et al. Protein-losing enteropathy after the Fontan operation. J Thorac Cardiovasc Surg 1996;112:672-80.

2. Malcic I, Sauer U, Brodherr S, et al. Protein-losing enteropathy after Fontan operation (abstract). Cardiol Young 1995; 5(suppl):S28.

3. Cetta F, Feldt R, O'Leary P, et al. Improved early morbidity and mortality after Fontan operation: the Mayo Clinic experience, 1987 to 1992. J Am Coll Cardiol 1996; 28:480-6.

4. Wilkinson P, Pinto B, Senior J. Reversible protein-losing enteropathy with intestinal lymphangiectasia secondary to chronic constrictive pericarditis. N Engl J Med 1965;273: 1178-81.

5. Davidson J, Waldmann T, Goodman D, Gordon R. Proteinlosing enteropathy in congestive heart failure. Lancet 1961; 1:899-902.

6. Moodie D, Feldt R, Wallace R. Transient protein-losing enteropathy secondary to elevated caval pressures and caval obstruction after the Mustard procedure. J Thorac Cardiovasc Surg 1976;72:379-82.

7. Gleason WJ, Roodman S, Laks H. Protein-losing enteropathy and intestinal lymphangiectasia after superior vena cavaright pulmonary artery (Glenn) shunt. J Thorac Cardiovasc Surg 1979;77:843-6.

8. Davis C, Driscoll D, Perrault J, et al. Enteric protein loss after the Fontan operation. Mayo Clin Proc 1994;69:112-4.

9. Crupi G, Locatelli G, Tiraboshi R, Villani M, De Tomassi M, Parenzan L. Protein-losing enteropathy after Fontan operation for tricuspid atresia (imperforate tricuspid valve). Thorac Cardiovasc Surg 1980;28:359-63.

10. Hess J, Kruizinga K, Bijleveld CMA, Hardjowijono R, Eygelaar A. Protein-losing enteropathy after the Fontan operation. J Thorac Cardiovasc Surg 1984;88:606-9.

11. Thorne S, Hooper J, Somerville J. Gastrointestinal protein loss in long term survivors of the Fontan operation (abstract). Br Heart J 1995;73(suppl):55.
12. Rothman A, Snyder J. Protein-losing enteropathy following the Fontan operation: resolution with prednisone therapy. Am Heart J 1991;121:618-9.

13. Rychik J, Piccoli D, Barber G. Usefulness of corticosteroid therapy for protein-losing enteropathy after the Fontan procedure. Am J Cardiol 1991;68:819-21.

14. Zellers T, Brown K. Protein-losing enteropathy after the modified Fontan operation: oral prednisone treatment with biopsy and laboratory proved improvement. Pediatr Cardiol 1996;17:115-7.

15. Murch S, Winyard P, Koletzko S, et al. Congenital enterocyte heparin sulphate deficiency with massive albumin loss, secretory diarrhoea, and malnutrition. Lancet 1996;347:1299-301.

16. Mertens L, Dumoulin M, Gewillig M. Percutaneous fenestration of the atrial septum reduces protein-losing enteropathy after the Fontan operation. Br Heart J 1994;72:591-2.

17. Warnes C, Feldt R, Hagler D. Protein-losing enteropathy after the Fontan operation: successful treatment by percutaneous fenestration of the atrial septum. Mayo Clin Proc 1996;71:378-9.

18. Jacobs M, Rychik J, Byrum C, Norwood WJ. Protein-losing enteropathy after the Fontan operation: resolution after baffle fenestration. Ann Thorac Surg 1996;61:206-8.

19. Donnelly J, Rosenthal A, Castle V, Holmes R. Reversal of protein-losing enteropathy with heparin therapy in three patients with univentricular hearts and Fontan palliation. J Pediatrics 1997;130:474-8.

20. de Leval M, Kilner P, Gewillig M, Bull C. Total cavopulmonary connection: a logical alternative to atriopulmonary connection for complex Fontan operations. J Thorac Cardiovasc Surg 1988;96:682-95.

21. de Leval M, Dubini G, Migliavacca F, et al. Use of computational flow dynamics in the design of surgical procedures: application to the study of competitive flows in cavopulmonary connections. J Thorac Cardiovasc Surg 1996;111:502-13.

22. Van Haesdonck J, Mertens L, Montas G, et al. Comparison by computerized numeric modeling of energy losses in different Fontan connections. Circulation 1995;9(Suppl): II322-6.

23. Sharma S, Goudy S, Walker P, et al. In vitro flow experiments for determination of optimal geometry of total cavopulmonary connection for surgical repair of children with functional single ventricle. J Am Coll Cardiol 1996;27:1264-9.

24. Rychik J, Suh E, Rome J, Jacobs M. Experience with late fenestration for complications after the Fontan operation (abstract). Circulation 1996;94(Suppl):I296.

25. Gewillig M, Mertens L, Stockx L. Percutaneous fenestration of the atrial septum with a stent. Eur J Cardiac Interventions $1995 ; 4: 122-5$

\section{List of participating physicians and centers}

Australia: G. Sholler, New Children's Hospital, Sidney; Belgium: P. Viart, Hôpital Universitaire des Enfants Reine Fabiola, Brussels; H. Verhaaren, University Hospital Gent; M. Gewillig and L. Mertens, University Hospital Leuven (KU Leuven); Canada: I. Adatia, R. Freedom, Hospital for Sick Children, Toronto; Croatia: I. Malcic, University Hospital Rebro, Zagreb; Czech Republic: J. Hruda, Kardiocenter Prague; Denmark: J.R. Jacobsen, Rigshospitalet, Copenhagen; France: G. Vaksmann and J. Rey, Hôpital Universitaire de Lille; A.M. Worms, Hôpital d'Enfants, Nancy; J. Kachaner, Hôpital Necker, Paris; J. 
Martinez, Hôpital Pasteur, Toulouse; Germany: U.Sauer, Deutsches Herzzentrum München; F. Hentrich, University Hospital Essen; D. Bartmus and R. Buchhorn, University Hospital Göttingen; T. Paul, University Hospital Hannover; P. Schneider, J. Theile and I. Wagner, University Hospital Leipzig; Greece: S. Pallides, Thessaloniki Hospital; Italy: G. Vignati, Ospedale San Donato Milano; Japan: T. Shinohara, Tokyo Women's Medical College; Turkey: A. Sarioglu, Istanbul University Hospital; United Kingdom: E. Rosenthal, Guy's Hospital, London; J. Somerville, Royal Brompton Hospital (GUCH unit), London; N. Wilson, Royal Hospital for Sick Children, Glasgow; G.
Stuart, University Hospital of Wales, Cardiff; United States: D.J. Hagler Mayo Clinic, Rochester; Dr. S. Gullquist, Medical College of Virginia, Richmond; $\mathrm{H}$. Weber, Penn State University Children's Hospital, Hershey; T. Bricker, Texas Children's Hospital, Houston; J.M. Baffa, University of Maryland Medical Center, Baltimore; K.S. Rheuban, University of Virginia Health Sciences Center, Charlottesville; Spain: J. Casadaliga, Hospital Materno-Infantil Valle Hebron, Barcelona; Sweden: Dr. K. Hanseus, University Hospital Lund; The Netherlands: A. Cromme Dijkhuis, Sophia Children's Hospital Rotterdam 